\title{
Creating positive synergies between risk management and transfer to accelerate food system climate resilience
}

\author{
Shahbaz Mushtaq, et al. [full author details at the end of the article]
}

Received: 2 May 2019 / Accepted: 17 February 2020 / Published online: 2 March 2020

(C) Springer Nature B.V. 2020

\begin{abstract}
Climate change will significantly impact the future viability and security of food production systems, with increased frequency and intensity of droughts, floods, storms and other extreme climatic events predicted in many regions. In order for food production systems to remain viable and resilient under a changing climate, novel approaches, which integrate risk management (i.e. adaptation) and risk transfer strategies, such as insurance, are required. We argue that the coordinated integration of risk management and risk transfer approaches will support greater resilience of food production systems under climate change. Conversely, if risk management and risk transfer strategies are not carefully integrated, there is potential to undermine adaptive capacity (e.g. insurance subsidies may dissuade farmers from investing in climate adaptation) and ultimately reduce the capacity of food production systems to cope with and recover from the adverse impacts of climate change. Here we propose a resilience-based conceptual framework for integrating risk management and risk transfer strategies along with four key principles, which we believe could underlie their successful integration and thus enhance food production system resilience under climate change. These are as follows: (1) pro-active investments in farmer climate adaptation rather than re-active disaster relief, (2) structuring of government subsidies around insurance and climate disaster relief to incentivise farmer climate adaptation, (3) rewarding farmer efforts towards climate adaptation with cheaper insurance premiums for those farmers that invest resources into climate adaptation and (4) recognising investments in the integration of farm climate adaptation and risk transfer schemes within the broader context of future climate disaster risk management and global food security. Such an integrated investment approach could substantially reduce future economic losses for farmers while also enhancing food security under climate change.
\end{abstract}

Keywords Climate change $\cdot$ Adaptation $\cdot$ Risk transfer $\cdot$ Extreme climate $\cdot$ Drought $\cdot$ Resilience . Insurance

\section{Introduction}

A key challenge in the coming decades will be developing strategies that support food producers to adapt so that they can effectively cope with the rate and nature of detrimental 
climatic changes (Lobell et al. 2008; Dovers and Hezri 2010; Dow et al. 2013). If future climatic change is incrementally small, farmers may autonomously adapt — as they have done historically - by adjusting and improving their agronomic techniques and marketing strategies (Moss et al. 2010; Kates et al. 2012; Chatzopoulos and Lippert 2015). However, there is concern that climate change may be neither gradual nor linear and that, therefore, such gradual adaptation may be insufficient, on its own, to meet future climate challenges (Howden et al. 2007; Moss et al. 2010; Kates et al. 2012; Park et al. 2012; Vermeulen et al. 2013;).

In search of a strategic response to climate risk, and recognising the role of proactive risk management and risk transfer through insurance mechanisms, the International Panel on Climate Change (IPCC) has stressed the need for a comprehensive integrated strategy to foster resilient production systems and rural communities (IPCC 2012). Although there is limited published information available, it is suggested that climate insurance can enhance resilience, but only if it is part of a wider adaptation strategy (e.g. insurance being bundled with credit), rather than being considered in isolation, or worse, as an alternative to adaptation (Carter et al. 2016; Greatrex et al. 2015). Extending this thinking to food production systems, we argue that carefully planned and integrated proactive measures based on coordinated risk management and risk transfer are required to cope with the risks of rapid and potentially non-linear climate change.

Important opportunities to create synergies between the finance sector for disaster risk management and adaptation to climate change exist but have not yet been fully realised. Coordination between risk management and risk transfer has been lacking, which has led to fragmented implementation. Without a robust approach to coordination, especially to accommodate the diverse perspectives of public and private entities, it will be hard to achieve the required level of resilience in regional or global food systems to accommodate the increasing level of risk associated with projected climate change. In response, our research aims to develop a conceptual framework for building long-term resilience to future climate risk by explicitly synthesising the synergies between risk management and risk transfer, providing a basis for hypothesis development and empirical testing.

The conceptual framework we propose is predicated on several assumptions. First, we assume strong mitigation actions to hold climate change warming to less than $2{ }^{\circ} \mathrm{C}$. Beyond this range, there will likely be severe limits to the ability of agricultural production systems to adapt (Klein et al. 2014) and hence on the utility of our proposed framework. Second, we focus on responses to extreme climatic events, defined here as climatic or weather conditions 'above (or below) a threshold value near the upper (or lower) ends of the range of observed values of the variable' (after IPCC 2012a). Third, our framework, which is conceptual in nature, is based on a synthesis of current theoretical and empirical research (e.g. Diaz et al., 2010; Kost et al. 2012), particularly as it applies to poor and vulnerable farmers with limited access to capital (of which there are millions globally).

\section{Linking risk management and risk transfer to accelerate climate resilience}

Improved climate resilience is increasingly a distinct policy objective used to promote targeted interventions aimed at supporting adaptation to climate change (Barrett and Constas 2014; Mushtaq 2018). Linkov et al. (2014) and the National Academy of Sciences (NAS) (National Research Council 2012) define resilience as "the ability to prepare and plan for, absorb, 
recover from, and more successfully adapt to adverse events". We acknowledge that this definition of resilience does not include the capacity for transformation (i.e. larger, intentional system change that alters the structure or function of the system sensu Carpenter et al. 2001 and Walker et al. 2004) and is limited to adaptive capacity within the system. We apply the dimensions of resilience outlined by NAS (2012) to food production systems as they relate to climate risk management (i.e. prepare, prevent and absorb), climate risk transfer (i.e. recovery through insurance) and improved climate adaptive capacity (i.e. increased ability to adapt to adverse events) (Fig. 1). Also, while there are several ways in which resilience might be measured, here we use co-indicators or proxies of resilience (i.e. technology adoption, farm size, financial resources) for the purpose of conceptualising the process of building resilience. Using this conceptual model, we focus on how risk management and risk transfer can be integrated to enhance adaptive capacity and in turn maximise resilience within agricultural production systems. We argue that, to achieve this, closely integrated risk transfer and risk management strategies will create positive (i.e. reinforcing) feedbacks that will increase the rate of adaptation to climate change, while also facilitating rapid recovery after unavoidable losses due to extreme climate events.

Risk management, preparation (Fig. 1a) and prevention (Fig. 1b) affect the magnitude of losses in food production systems impacted by extreme climatic events. For example, in livestock production systems, risk preparation strategies (Fig. 1a) might include the use of improved climate forecasts and trigger points to adjust livestock numbers to help prepare for drought. Early decisions to reduce livestock numbers (i.e. stocking rate) reduce the risk of pasture resource degradation, livestock weight loss and stock mortality and significantly improve pasture recovery when drought breaks (McKeon and Hall 2002). In addition, a timely and orderly disposal of livestock (i.e. destocking) avoids the inevitable crash in market price when many producers try to divest at the same time. Coupled with risk preparation, a risk prevention strategy (Fig. 1b) in the example of a grazing enterprise might include investment in water infrastructure to store and efficiently convey water, thereby reducing the negative impacts of drought (Frisvold et al. 2013). Those better prepared for the negative consequences of extreme climatic events will better be able to absorb shocks (Fig. 1c) and so have their productivity and profitability impacted to a lesser extent than other less resilient producers.

Farmers' ability to adopt new technologies and/or practices (i.e. engage in risk preparation and prevention) is constrained when resources (e.g. natural, human, social, physical and financial) are limited. At some point, the costs of adaptation that may outweigh the benefit to be gained from adapting and maintaining valued objectives (e.g. profit and rural livelihood) may become unfeasible (Dow et al. 2013; Vermeulen et al. 2013). When farmers are impacted by adverse climate conditions, especially low-frequency and high-severity events, risk transfer mechanisms (i.e. insurance) can provide a level of protection by smoothing the economic costs (i.e. losses) associated with the event and facilitating recovery (Skees et al. 2008).

Such risk sharing effectively transfers risk from the farmer to the insurance industry using contractual arrangements (Meuwissen et al. 2001). Risk transfer that facilitates recovery (Fig. 1d) allows a more rapid return to normal production following extreme climatic conditions. In the case of a grazing enterprise, the role of insurance would be to compensate for financial losses and facilitate pasture recovery and restocking, enabling producers to resume production. In addition to careful management to ensure land is not degraded, timely insurance payments (e.g. during drought events) may also be used to purchase fodder so that destocking is not required (e.g. Satellite Index Insurance for Pastoralists Ethiopia in (SIIPE) program (World Food Programme 2017)). 


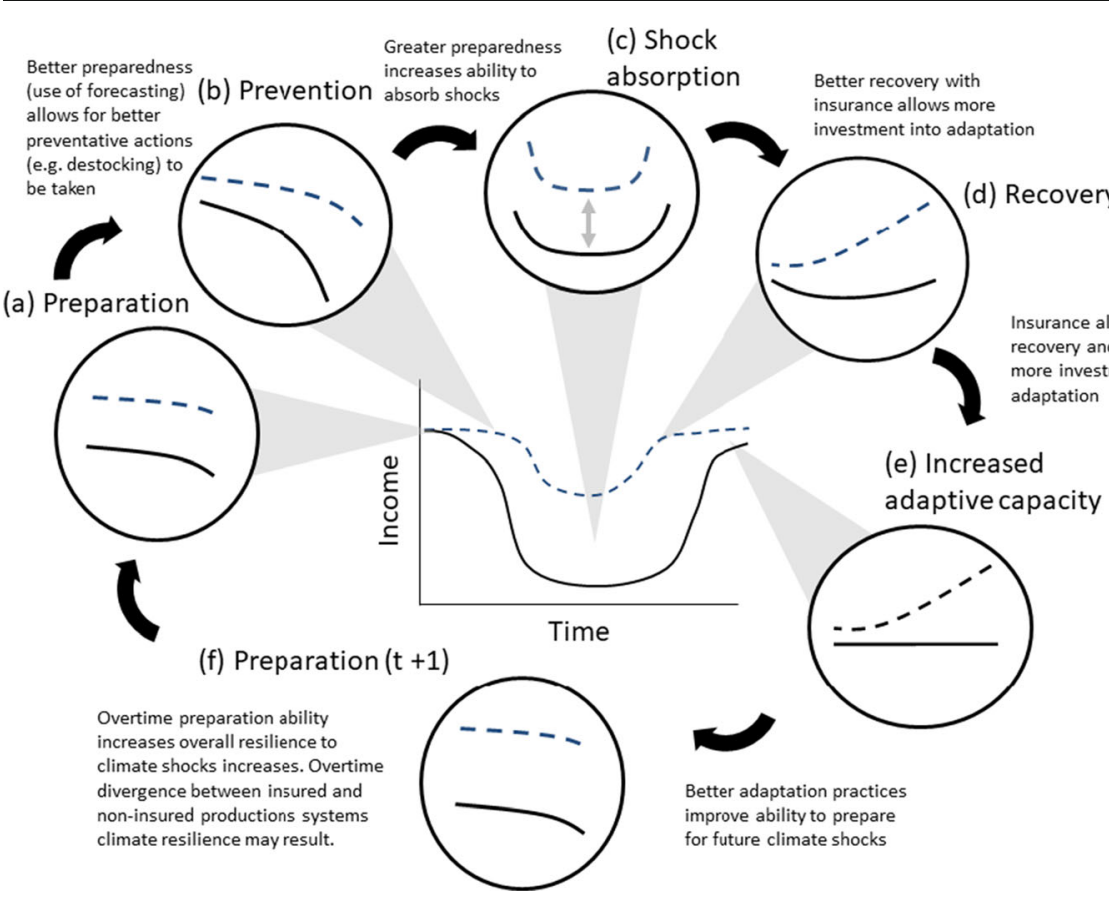

Fig. 1 Conceptual overview of the components of resilience showing the dynamic and iterative relationship between risk management (preparation,prevention and shock absorbtion), risk transfer (recovery through insurance) and improved adaptive capacity and how they foster increased climate resilience. The dashed blue line represents a resilient production system with robust risk management and transfer strategies, which prevent losses, allow quicker recovery, make available more resources for robust planning for adaptation and in turn increase preparedness to future climate shocks. The solid black line represents a non-resilient production systems. The components of resilience: (a) Preparation refers to the better use of climate information to manage extreme climate events; (b) prevention refers to the adoption of improved risk management practices; (c) shock abosrobtion indicates that resilient systems should show less dramatic declines in response to extreme climatic events; (d) recovery refers to the targetted use of insurance that would allow producers to recover quickly after an extreme climatic event; (e) increased adaptive capacity allows producers to take advantage of favourable climatic conditions and/or continue investment in further climate adaptation; and (f) preparation $(t+1)$ refers to accelerated resilience to better prepare for future climate risks

Currently, post-disaster recovery is often funded through various aid/subsidy programs. However, our suggested integrated risk management and risk transfer model propose a system in which adaptation is supported by proactive ex ante (public sector) support and residual risk is managed through insurance payouts (private sector) which underwrite the cost of recovery. Where catastrophic events occur, insurance can complement public sector aid programs by reducing the demand for government assistance.

In addition to facilitating recovery, insurance could also alleviate liquidity constraints, thereby allowing the adoption of new technology and practices (Carter and Barrett 2006; Freudenreich and Mußhoff 2018). The proponents of climate risk insurance argue that insurance could facilitate faster recovery by making capital available for re-investment into adaptation measures (Fig. 1e), thus potentially building future resilience at desired scales (Linnerooth-Bayer and Hochrainer-Stigler 2015; Surminski et al. 2016). Nevertheless, we acknowledge that, even with the availability of finance through insurance, transaction costs; 
cultural, institutional and behavioural/socio-psychological obstacles to adaptation; and the high cost of insurance premiums may still impede investment in new technologies and adoption of improved practices (Adger et al. 2009; Jantarasami et al. 2010; Nelson et al. 2010).

High insurance premiums, especially for products such as Multi-Peril Crop Insurance (MCPI), are a major factor limiting the potential adoption of insurance products (Kath et al. 2019). While large commercial farms have some capacity to offset financial risks with insurance, most smallholders, including subsistence farmers, may be unable to meet the cost of insurance. Indeed, the majority of MCPI schemes around the world require government subsidies in order to function (Schaefer and Waters 2016). However, recently, index-based insurance products, where payouts are related to an 'index' (e.g. rainfall, temperature), have been seen as a cost-effective replacement of MCPI. One advantage of index-based insurance is a substantial reduction $(\sim 30-35 \%)$ in transaction costs due to elimination of the need for expensive post-event claims handling, which has impeded the development of insurance mechanisms in developing countries (Varangis et al. 2002). A disadvantage is basis risk, which is the lack of correlation of the trigger with the loss incurred.

Insurance can also shift financial resources away from ad hoc post-event payments, where funding is often unpredictable and delayed, towards more strategic and, in many cases, more efficient approaches planned or set up in advance of significant events (Linnerooth-Bayer and Hochrainer-Stigler 2015; Surminski et al. 2016).

More resilient production systems are expected to sustain less damage and to recover more quickly when exposed to climate risk. For example, production systems with high resilience (the blue dotted lines in Fig. 1) will perform better than those with low resilience (the black lines in Fig. 1) facing similar risks. This greater resilience is due to the fact that farms which adopt improved risk management strategies to cope with extreme climate events sustain less damage and also recover more rapidly, especially where supported by suitable risk transfer mechanisms. The greater financial flexibility offered, especially by speedy insurance payouts, means farmers can increase their adaptive capacity by further investing in innovative solutions and/or take advantage of more favourable weather conditions following the event, thus minimising opportunity costs (Fig. 1e) (Engle 2011).

Importantly, in developing countries, reduced financial losses and speedy recovery mean that poor farmers are better positioned to escape poverty traps. Schaefer and Waters (2016) provide a detailed synthesis, including evidence from historical studies, to demonstrate how insurance could potentially benefit pro-poor socio-economics. According to Schaefer and Waters (2016), at the microlevel, insurance can help to unlock opportunities and may help increase savings, increase investments in higher-return activities and improve creditworthiness, all of which might allow people to escape from poverty traps or from the threat of them. Initial assessment of the World Food Programme, the R4 Rural Resilience Initiative, shows that insurance is helping to improve farmers' resilience. For example, in Ethiopia, insured farmers save more than twice as much as those without any insurance, and they invest more in seeds, fertilisers and productive assets.

Increased investment in adaptive capacity will further increase resilience making food production systems better prepared for future climate shocks (Fig. 1f) (Linkov et al. 2014). At the macro-level, research suggests that insurance may contribute to economic growth that could be used to increase investments in adaptive capacity, by allowing for more effective risk management. Analyses of 2500 natural catastrophes that occurred between 1960 and 2011 in 
over 203 countries provide evidence that the insurance sector contributed to economic growth (Lester 2014; Arena 2008).

Finally we conceptualise this process as iterative (Fig. 1), with increased adaptive capacity ultimately increasing farmers' preparedness and ability to withstand further climate shocks, which in turn allows them to further invest in increasing adaptive capacity so in effect they are continually working to increase the climate resilience of their production system.

\section{Conceptualising the implications of risk management and risk transfer integration for food production system resilience under climate change}

A 'resilience' concept for food systems involves equipping farmers with the ability to absorb and recover from all kinds of shocks to their farming system and livelihoods, including pest and disease outbreaks, supply chain and market disruptions, as well as extreme climate events. 'Climate resilience', on which this paper specifically focuses, is concerned with building adaptive capacity to the stresses of extreme climate events, examples of which include heat waves, frost, drought, flood and hail. Continuous adaptation in agricultural production systems is fundamental to improving the resilience, including climate resilience, of these systems and ensuring livelihood and, more generally, food security.

In this section, we explore the implications of different scenarios of risk management and risk transfer integration for food production system resilience under climate change. We acknowledge that a huge body of literature is currently looking at the drivers of technology adoption and challenges related to agricultural insurance, especially related to index-based insurance and scaling up insurance schemes (e.g. Chen et al. 2018; Greatrex et al. 2015). Here, instead, we focus on how risk management (technology, improved practices) and risk transfer (insurance) might be conceptually integrated. We present four generalised qualitative scenarios of how food production system losses from weather and climate disasters may play out under climate change.

Scenarios with and without the presence of risk management and risk transfer integration are shown in Fig. 2a. Alongside each scenario, the corresponding farm losses and changing farm compositions are shown in Fig. $2 b$.

The first panel (Fig. 2a (i)) indicates a scenario where a farmer fails to implement risk management strategies. He/she may not incorporate seasonal climate forecasts in his/her planning decisions but instead makes decisions based on the historical climate, which under climate change may be insufficient. The farmer neither has made investments in managing climate risk or preparing for extreme climate events nor has insurance been purchased to cover losses from extreme events. To cope with weather risks and cover production losses, the farmer relies on post-disaster government support (e.g. drought relief assistance) or in the case of developing countries, international aid. This type of farmer has very low climate resilience into the future (Fig. 2a (i)). This scenario is not sustainable, either in the short or longer term, given risks from current climate variability and future climate change. As a consequence of low resilience and lack of adaptation strategies, we anticipate that such farmers (grey circles) will swiftly exit the industry in the near future. Farmers with greater equity, less debt, more resources and economies of scale (blue circles) will continue to produce in the short to midterm but as climate change intensifies will also likely exit the production system (Fig. 2b (i)).

The second panel (Fig. 2a (ii)) represents a scenario where a farmer has made no investments in minimising climate impacts but has purchased insurance to cover losses from 


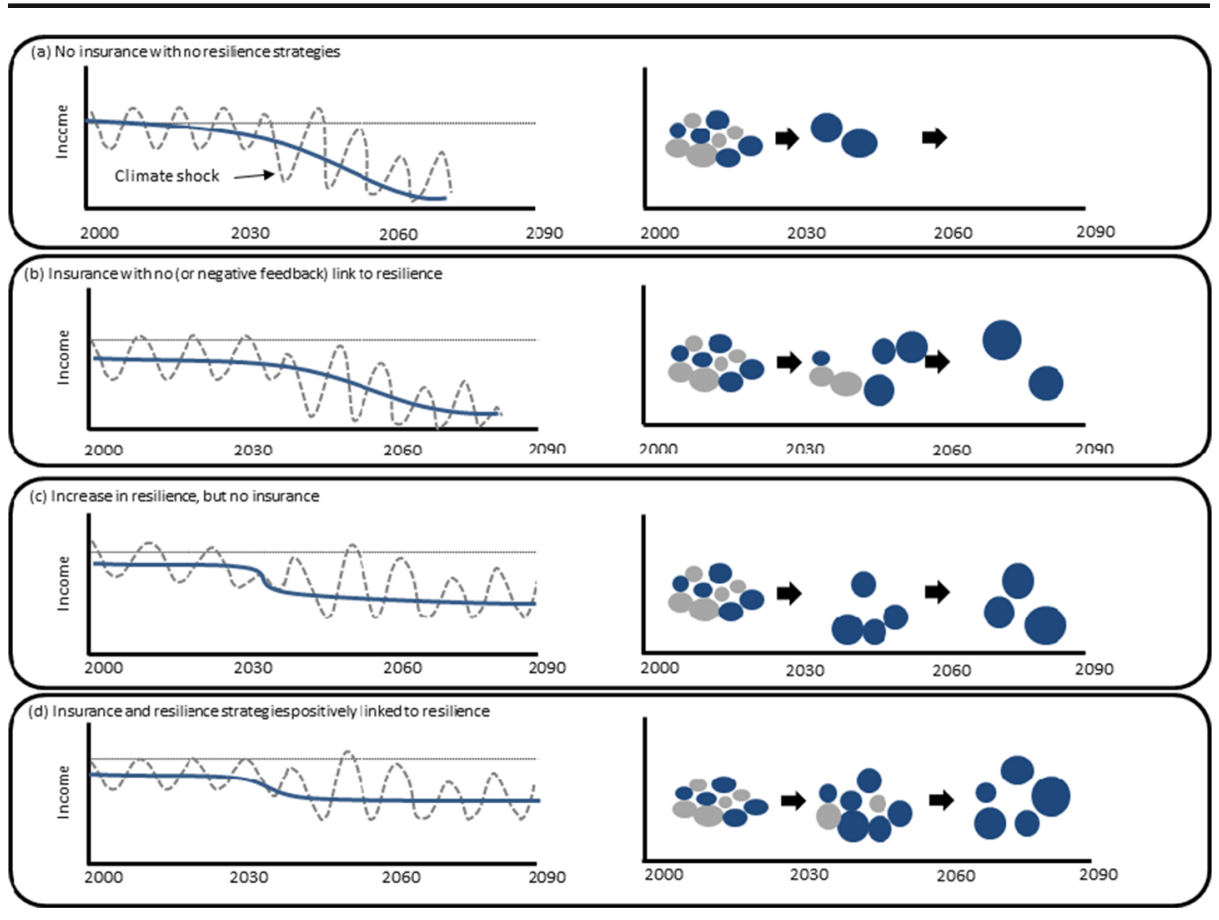

Fig. 2 Conceptulisation of the possible outcomes of four different broad integration strategies. Left-hand side shows changes in income as climate change intensifies through time (grey dashed lines represent the likely volatile nature of this change and the solid blue line the trend). Right-hand side figures show how the composition of producers may change under different scenarios. Blue circles are resilient producers grey circles are not resilient and larger circles reflect greater resilience to survive under predicted climate change. Scenarios are as follows: a No use of resilience and insurance strategeis to help producers adapt to future climatic changes - likely to led to a steady decline in production and income as time progresses and the loss of producers from the food production system; $\mathbf{b}$ insurance used by itself - farmer recovery to extreme climate events in the short term may be assisted, but this will not foster increased climate resilience and so over time incomes will decline as insurance premiums increase and only large producers who are able to 'self-insure' will remain in the system; c no use of insurance - inhibits rapid recovery and increases uncertainity, which may inhibit investment in climate adaptation stratagies and so over time incomes will decline and only large producers are able to manage climate risks (e.g. through spatial diversification) will be able to persist; and $\mathbf{d}$ integration of insurance and resilience increasing strategies helps stabilise production and farmer incomes and allows non-resilient producers to transition to resilient producers, over the longer term allowing a greater number of producers to persist

extreme weather events. However, access to insurance without appropriate risk management (i.e. prevention and preparation strategies) raises certain moral hazard problems and/or negative enabling conditions due to policy incentives (e.g. insurance subsidies, drought relief payments) and/or increasingly unaffordable insurance premiums. Ultimately, this approach could lead some farmers to adopt riskier production practices and to not invest in risk management strategies (Quiggin et al. 1993). For example, Smit and Skinner (2002) found that subsidised insured soybean producers in southern Ontario, Canada, were less diversified and had lower levels of off-farm income compared with uninsured producers, while in Malawi, subsidised insurance reduced adoption of new and possibly more adaptive crops (Giné and Yang 2009). Removal of insurance subsidies in New Zealand modified producers' risk behaviour, causing them to abandon climate-sensitive crops in risk-prone areas and diversify products and inputs to better manage climate risks (Smit 1994). The second scenario (Fig. $2 \mathrm{a}$ 
(ii)), where the farmer relies on insurance only (and thus does not invest in increased adaptive capacity), is only viable over the short term.

Lack of investment in prevention and preparation, exacerbated by subsidised insurance, means losses will most likely increase as climate change intensifies. In turn, insurance premiums will likely increase over time to cover the increased climate risk and, eventually, will become too costly. Possibly, then, if underlying climate risks are not addressed through mitigation and/or adaptation, risks will become uninsurable (Surminski et al. 2016). As such, with access to insurance only, non-resilient farms (grey circle) will exit the production system in the long-run, with only a small sub-set of resilient farms (blue circles) expected to survive in the long-run (Fig. 2b (ii)). An important aspect of long-term resilience is structural adjustment (Mushtaq et al. 2013), especially in terms of farm size (as shown in relatively larger blue circles in the longrun) to allow the benefits of economies of scale to be realised.

The third panel (Fig. 2a (iii)) describes a scenario where a farmer has made considerable climate adaptation investments (e.g. water storage, irrigation systems, soil moisture monitoring probes) to prepare for extreme weather events but has not purchased insurance to cover residual losses that cannot be adapted for through risk management. Despite suitable investment in the production system, without insurance, the farmer may continue to be productive with minimum production losses in the short term; however, over the long term, after approaching limits to adaptation (Dow et al. 2013; Vermeulen et al. 2013), production losses will continue to increase, forcing the farmer eventually to exit farming. An important feature of risk management investment is that it allows larger sub-sets of highly resilient farms to persist in the long-run (Fig. 2b (iii)). A major point to note is that the number of resilient farms (blue circles) sustaining food production systems in the long-run is higher than those solely relying on risk transfer (Fig. 2b (ii)). This is due to the fact that, when compared with risk transfer options, risk management has better sustainability and welfare implications (Müller et al. 2017).

The fourth panel (Fig. 2a (iv)) describes an ideal scenario where a farmer makes ongoing investments into mitigating climate risk and preparing for extreme weather events, while also using insurance to cover extreme weather risk losses that cannot be prevented. An optimal combination of risk management, risk transfer and improved adaptive capacity will transform the production system into one sufficiently resilient to cope with climate change (Fig. 2a (iv)). Insurance helps in managing short-term climate risk through speedy recovery, while also allowing investors to capitalise on favourable climate outlooks by offering the necessary liquidity to enable re-investment in risk management (prevention and preparation) strategies (Freudenreich and Mußhoff 2018). Positive enabling environments, such as activities that reduce agricultural risk, could allow the private sector to offer more affordable insurance premiums and financial market interest rates, which will be critical in encouraging farmers to purchase insurance contracts (World Bank 2018). Carter et al. (2016) have shown, theoretically, that by linking credit with index insurance, contractual interest rates could be reduced, positively impacting the adoption of improved technologies. Increasing farmer resilience also potentially means insurance premiums will largely remain stable or decrease over time, even after accounting for increasing risk associated with climate change (Hudson et al. 2016). Under this scenario, a diverse range of farmers is expected to persist in the food production system under climate change (Fig. 2b (iv)). 


\section{Linking risk transfer and risk management to accelerate food production system climate resilience}

The key distinction between the scenarios presented above is whether risk management and risk transfer activities create conditions that either encourage or inhibit investment into adaptation activities addressing climate change risk. Resilience inhibiting conditions (scenarios in Fig. 2a (i) and (ii)) could create moral hazards, policy incentives that encourage riskier production and a lack of investment in risk reducing technology, which in turn mean higher vulnerability to extreme climate events and thus higher future insurance premiums (Müller et al. 2017; Freudenreich and Mußhoff 2018). On the other hand, resilience enhancing conditions (scenarios in Fig. 2a (iii) and (iv)) could include insurance contracts that positively encourage adoption of best management practices and technology or, alternatively, more affordable premiums due to investments in risk management strategies (see Carter et al. 2016; Panda et al. 2013; Freudenreich and Mußhoff 2018). Below, we outline four key principles, which we believe would help successfully integrate risk management and risk transfer approaches to enable greater climate resilience in food production systems (these are summarised in Table 1).

First is a preference towards proactive investments in climate adaptation, rather than reactive climate disaster relief payments. In this regard, the public sector plays a crucial role in developing proactive (ex-ante) policies, focusing on improving climate risk prevention and preparation aspects of production systems rather than reactive (ex-post) disaster relief programs. Government subsidies, which effectively act as reactive disaster relief, may simply crowd out private sector interests (Arrow 1996; Skees 2000). In Australia alone, over AUD 2 billion (US $\$ 1.46$ billion) in drought relief assistance payments to producers have been made in the last 28 years. Government subsidies can also cause significant inefficiencies, some of which may have negative environmental consequences, especially for agriculturally important natural resources such as water and soil (Nelson et al. 2008).

Here, we advocate that insurance be complementary to the more conventional post-disaster response. We argue that it not only helps to reduce post-disaster aid, but, more specifically, it

Table 1 The four general principles that could underlie successful integration of risk management and risk transfer to increase food production system long-term climate resilience

Principles Current approach: climate vulnerable agricultural Suggested principle; climate resilient agricultural and insurance industry and insurance industry

1 The current approaches to natural disasters are heavily weighted toward subsidies and reactive disaster relief programs and payments

Dissuade risk adaptation by the agricultural industry

Potentially 'crowd-out' the insurance industry. Low uptake of insurance policies.

Increase in disaster relief needs and associated payments, and potential for risks to become uninsurable as climate change intensifies placing further burden on governments/NGOs in climate disaster recovery
Pro-active strategies that increase climate risk preparation and presentation capabilities - improving adaptive capacity Improved farmer adaptation to climate risks and likely improvement in overall management (e.g. BMPs)

Reduces overall risk of insuring farmers and allows insurance industry to provide more affordable premiums. High uptake of insurance policies.

Reduced magnitude of disaster relief payments (e.g. drought relief payment) and potential positive outcomes in terms of agricultural and environmental sustainability. Overall improvements in societal welfare. 
will also support improved resilience to disasters through a combination of an ex-ante portfolio of actions to minimise risks (supported by governments) and with remaining/residual risk shifted to the financial sector (insurance companies). A key point to note is that post-disaster aid can deter producers from developing risk management plans and/or purchasing insurance products. This often results in crowding out of the insurance program, resulting in very low uptake of the insurance products. By contrast, simple, flexible and affordable risk transfer options such as index-based insurance can provide much needed, immediate liquidity after a disaster; provide some relief from the fiscal burden placed on governments due to disaster impacts; allow for more effective government response; and constitute critical steps in promoting more proactive risk management strategies and responses (Arnold 2008).

Second, any government subsidies around weather insurance should be structured so that they incentivise farmer climate adaptation. Risk-based insurance premiums and associated pricing structures could promote positive behaviour among producers and encourage them to invest in climate adaptation if this was linked to reduced premiums (Hecht 2008; Carter et al. 2016). Price signals set by risk-based premiums are expected to drive continued investments in innovative solutions. For example, insurance premiums could be lower for those producers that follow Best Management Practices and have improved risk management investments/ plans. The increasing adoption of quality assurance and performance accreditation schemes in agricultural production such as ISO 14001 (Salim et al. 2018) is likely to assist stakeholders in documenting and justifying risk-based adjustments to insurance costs. Thus, while insurance will help to transfer risk and aid recovery, continued investment in improved adaptation is crucial to making climate risks more manageable and to achieving overall improvements in social welfare.

Thirdly, farmer efforts towards climate adaptation should be acknowledged and encouraged by linking insurance premiums to risk reduction. Given that access to credit is positively associated with adopting adaptation practices (Ali and Erenstein 2017), improved adaptation and access to insurance may encourage banks to reduce interest rates or other costs, since such changes will have a positive impact on portfolio risks (World Bank 2018). Risk management and risk transfer are mutually reinforcing. Well-targeted proactive investments aimed at improving climate resilience - through investment in infrastructure, technology advances, capacity improvements, shifts in systems, management practices and behaviour - integrated with targeted insurance programs will result in accelerated resilience in the long-run. Importantly, this will prevent 'crowding out', possibly resulting in 'crowding in' (Jensen and Barrett 2017; Carter et al. 2016), and provide suitable enabling conditions for risk-sharing between the private and public sectors. More significantly, continued proactive targeted investments would act to keep insurance premiums in check by minimising residual risks. Additionally, insurance can play a critical quasi-regulatory role to counteract weak enforcement of regulatory standards. For example, insurance could influence a producer's behaviour to adopt BMPs developed for key agricultural industries to achieve improved sustainable production and environmental outcomes.

Fourth, and finally, investments in improved farmer climate resilience, and associated risk transfer schemes that encourage this, should be viewed within the broader context of climate disaster risk management and global food security. Commonly, public policies for addressing disaster risks are expected to be more consistent with long-term objectives if they are developed in advance of the loss events (Phaup and Kirschner 2010). Over the long run, such ex-ante adaptation/risk management policies, together with risk transfer options, would be expected to reduce future relief and recovery costs and increase fiscal stability and long-term well-being in the face of climate change and associated extreme climate events. 


\section{Conclusions}

Effectively managing increased climate risk will require food production systems to adopt well-coordinated integrated approaches to risk management. The coordinated integration of appropriately designed risk management and risk transfer approaches discussed in this paper has the potential to support greater resilience in food production systems under climate change. Without careful consideration of how these strategies are implemented, there is potential for unintended consequences that may undermine adaptive capacity (e.g. subsidies may dissuade farmers from investing in climate adaptation) and ultimately reduce the ability of food production systems to cope with and recover from the adverse impacts of climate change.

Farmers' ability to adopt new technologies and practices (i.e. engage in risk preparation and prevention) is constrained when resources are limited. In addition, at some point, the costs of adaptation will likely outweigh the benefits. When adaptation becomes economically unviable, as may occur with more extreme events under climate change, then it is often financially suitable to transfer risks through suitable insurance mechanisms. Here, we proposed a resilience based conceptual framework for integrating risk management and risk transfer strategies along with four key principles, which we propose could motivate their successful integration and thus enhance food production system resilience under climate change. These principles are as follows: (1) pro-active investments in farmer climate adaptation rather than re-active disaster relief, (2) structuring of government subsidies around insurance and climate disaster relief to incentivise farmer climate adaptation, (3) rewarding farmer efforts towards climate adaptation with cheaper insurance premiums for those farmers that invest resources into climate adaptation and (4) recognising investments in the integration of farm climate adaptation and risk transfer schemes within the broader context of future climate disaster risk management and global food security. Such an integrated investment approach could substantially reduce future economic losses for farmers while also enhancing food security under climate change.

Acknowledgements Special thanks to Julian Roberts from Willis Towers Watson for his valuable comments.

Funding information This research is funded through the Queensland Government's Drought and Climate Adaptation Program (DCAP) and the German Federal Ministry for the Environment, Nature Conservation, Building and Nuclear Safety (BMUB) through the International Climate Initiative (IKI). This work was also implemented as part of the CGIAR Research Program on Climate Change, Agriculture and Food Security (CCAFS), which is carried out with support from CGIAR Fund Donors and through bilateral funding agreements. For details, please visit https:/ccafs.cgiar.org/donors. David Cobon is supported by the Northern Australia Climate Program funded by Meat and Livestock Australia Donor Company, DCAP and the University of Southern Queensland.

\section{References}

Adger WN, Dessai S, Goulden M, Hulme M, Lorenzoni I, Nelson DR, Naess LO, Wolf J, Wreford A (2009) Are there social limits to adaptation to climate change? Clim Chang 93(3-4):335-354

Ali A, Erenstein O (2017) Assessing farmer use of climate change adaptation practices and impacts on food security and poverty in Pakistan. Clim Risk Manag 16:183-194

Arena M (2008) Does insurance market activity promote economic growth? A cross-country study for industrialized and developing countries. Journal of Risk and Insurance 75(4):921-946

Arnold M (2008) The role of risk transfer and insurance in disaster risk reduction and climate change adaptation. Policy brief, Commission on Climate Change and Development, Stockholm

Arrow KJ (1996) The theory of risk-bearing: small and great risks. J Risk Uncertain 12(2/3):103-111 
Barrett BC, Constas AM (2014) Toward a theory of resilience for international development applications. Proc Natl Acad Sci 111(40):14625-14630

Carpenter S, Walker B, Anderies JM, Abel N (2001) From metaphor to measurement: resilience of what to what? Ecosystems 4:765. https://doi.org/10.1007/s10021-001-0045-9

Carter M, Barrett C (2006) The economics of poverty traps and persistent poverty: an asset based approach. J Dev Stud 42:178-199

Carter RM, Cheng L, Sarris M (2016) Where and how index insurance can boost the adoption of improved agricultural technologies. J Dev Econ 118:59-71

Chatzopoulos T, Lippert C (2015) Adaptation and climate change impacts: a structural ricardian analysis of farm types in Germany. J Agric Econ 66(2):537-554

Chen M, Wichmann B, Luckert M, Winowiecki L, Forch W, Laderach P (2018) Diversification and intensification of agricultural adaptation from global to local scales. PLOS One 13/5:e196392

Dovers RS, Hezri AA (2010) Institutions and policy processes: the means to the ends of adaptation. Clim Chang $1: 212-231$

Dow K, Berkhout F, Preston LB, Klein TJR, Midgley G, Shaw RM (2013) Limits to adaptation. Nat Clim Chang 3:305-307

Engle NL (2011) Adaptive capacity and its assessment. Glob Environ Chang 21(2):647-656

Freudenreich $\mathrm{H}$, Mußhoff $\mathrm{O}$ (2018) Insurance for technology adoption: an experimental evaluation of schemes and subsidies with maize farmers in Mexico. J Agric Econ 69(1):96-120

Frisvold GB, Jackson LE, Pritchett JG, Ritten JP (2013) Agriculture and ranching. In: Garfin G, Jardine A, Merideth R, Black M, LeRoy S (eds) Assessment of Climate Change in the Southwest United States. A report prepared for the National Climate Assessment by Southwest Climate Alliance. Island Press, Washington, DC, pp 218-239

Giné X, Yang D (2009) Insurance, credit, and technology adoption: field experimental evidence from Malawi. J Dev Econ 89(1):1-11

Greatrex H, Hansen JW, Garvin S, Diro R, Blakeley S, Le Guen M, Rao KN, Osgood DE (2015) Scaling up index insurance for smallholder farmers: recent evidence and insights. CCAFS report no. 14. CGIAR Research Program on Climate Change, Agriculture and Food Security (CCAFS), Copenhagen

Hecht SB (2008) Climate change and the transformation of risk: insurance matters. UCLA Law Review 55(6). UCLA School of Law research paper no. 08-24

Howden SM, Soussana JF, Tubiello FN, Chhetri N, Dunlop M, Meinke H (2007) Adapting agriculture to climate change. Proc Natl Acad Sci 104:19691-19696

Hudson P, Botzen WJW, Feyen L, Aerts CJHJ (2016) Incentivising flood risk adaptation through risk based insurance premiums: trade-offs between affordability and risk reduction. Ecol Econ 125:1-13

IPCC (2012) Summary for policymakers. In: Field CB (ed) Managing the risks of extreme events and disasters to advance climate change adaptation. A special report of working groups I and II of the Intergovernmental Panel on Climate Change (IPCC). Cambridge University Press, Cambridge, pp 1-19

IPCC (2012a) Managing the risks of extreme events and disasters to advance climate change adaptation. In: Field CB, Barros V, Stocker TF, Qin D, Dokken DJ, Ebi KL, Mastrandrea MD, Mach KJ, Plattner G-K, Allen SK, Tignor M, Midgley PM (eds) A special report of Working Groups I and II of the Intergovernmental Panel on Climate Change. Cambridge University Press, Cambridge $582 \mathrm{pp}$

Jantarasami LC, Lawler JJ, Thomas CW (2010) Institutional barriers to climate change adaptation in U.S. national parks and forests. Ecology and Society 15(4):33

Jensen N, Barrett C (2017) Agricultural index insurance for development. Applied Economic Perspectives and Policy 39(2):199-219

Kates WR, Travis RW, Wilbanks JT (2012) Transformational adaptation when incremental adaptations to climate change are insufficient. Proc Natl Acad Sci 109:7156-7161

Kath J, Mushtaq S, Henry R, Kouadio L, Adeyinka A, Stone RC, Marcussen T (2019). Efficiency of rainfall index insurance for Australia's wheat regions. Climate Risk Management, vol 24. 2019, pp 13-29

Klein RJT, Midgley GF, Preston BL, Alam M, Berkhout FGH, Dow K, Shaw MR (2014) Adaptation opportunities, constraints, and limits. In: Climate change 2014: impacts, adaptation, and vulnerability part A: global and sectoral aspects. In: Field CB, Barros VR, Dokken DJ, Mach KJ, Mastrandrea MD, Bilir TE, Chatterjee M, Ebi KL, Estrada YO, Genova RC, Girma B, Kissel ES, Levy AN, MacCracken S, Mastrandrea PR, White LL (eds) Contribution of Working Group II to the Fifth Assessment Report of the Intergovernmental Panel on Climate Change. Cambridge University Press, Cambridge, pp 899-943

Kost A, Läderach P, Fisher M, Cook S, Gómez L (2012) Improving index-based drought insurance in varying topography: evaluating basis risk based on perceptions of Nicaraguan hillside farmers. PLoS One 7(12): e51412. https://doi.org/10.1371/journal.pone.0051412

Lester R (2014). Insurance and inclusive growth. Policy research working paper. No. 6943. The Word Bank. https://doi.org/10.1596/1813-9450-6943 
Linkov I, Bridges T, Creutzig F, Decker J, Fox-Lent C, Kröger W, Lambert HJ, Levermann A, Montreuil B, Nathwani J, Nyer R, Renn O, Scharte B, Scheffler A, Schreurs M, Thiel-Clemen T (2014) Changing the resilience paradigm. Nat Clim Chang 4:407-409

Linnerooth-Bayer J, Hochrainer-Stigler S (2015) Financial instruments for disaster risk management and climate change adaptation. Clim Chang 133:85-100

Lobell DB, Burke MB, Tebaldi C, Mastrandrea MD, Falcon PW, Naylor LR (2008) Prioritizing climate change adaptation needs for food security in 2030. Science 319:607-610

McKeon GM, Hall WB (2002) Can seasonal forecasting prevent land and pasture degradation? Final report for the climate variability in agriculture program. Land and Water Australia

Meuwissen MPM, Hardaker JB, Huirne RBM, Dijkhuizen AA (2001) Sharing risks in agriculture; principles and empirical results. Netherlunds Journal of Agricultural Science 49:343-356

Moss HR, Edmonds AJ, Hibbard AK, Manning RM, Rose KS, van Vuuren PD, Carter RT, Emori S, Kainuma M, Kram T, Meehl AG, Mitchel FBJ, Nakicenovic N, Riahi K, Smith JS, Stouffer JR, Thomson MA, Weyant PJ, Thomas JW (2010) The next generation of scenarios for climate change research and assessment. Nature 463:747-756

Müller B, Johnson L, Kreuera D (2017) Maladaptive outcomes of climate insurance in agriculture. Glob Environ Chang 46:23-33

Mushtaq S (2018) Managing climate risks through transformational adaptation: economic and policy implications for key production regions in Australia. Clim Risk Manag. https://doi.org/10.1016/j.crm.2017.12.001

Mushtaq S, Cockfield G, White N, Jakeman G (2013) Modelling interactions between farm-level structural adjustment and a regional economy: a case of the Australian rice industry. Agric Syst 123:34-42

National Research Council (2012). Disaster resilience: a national imperative. The National Academies Press, Washington, DC. https://doi.org/10.17226/13457

Nelson R, Howdon M, Smith SM (2008) Using adaptive governance to rethink the way science supports Australian drought policy. Environ Sci Pol 11(7):588-601

Nelson R, Kokic P, Crimp S, Meinke H, Howden SM (2010) The vulnerability of Australian rural communities to climate variability and change: Part I-Conceptualising and measuring vulnerability. Environ Sci Pol 13(1):8-17

Panda A, Sharma U, Ninan NK, Patt A (2013) Adaptive capacity contributing to improved agricultural productivity at the household level: empirical findings highlighting the importance of crop insurance. Glob Environ Chang 23:782-790

Park SE, Marshall NA, Jakku E, Dowd AM, Howden SM, Mendhamf E, Fleming A (2012) Informing adaptation responses to climate change through theories of transformation. Glob Environ Chang 22:115-126

Phaup M, Kirschner C (2010) Budgeting for disasters: focusing on the good times. OECD Journal on Budgeting 2010(1):1-24

Quiggin CJ, Karagiannis G, Stanton J (1993) Crop insurance and crop production: an empirical study of moral hazard and adverse selection. Aust J Agric Econ 37(2):95-113

Salim HK, Padfield R, Hansen SB, Mohamad SE, Yuzir A, Syayuti K, Tham MH, Papargyropoulou E (2018) Global trends in environmental management system and ISO14001 research. J Clean Prod 170:645-653

Schaefer L, Waters E (2016) Climate risk insurance for the poor \& vulnerable: how to effectively implement the pro-poor focus of InsuResilience. Access on 28 September 2019 at http://www.climate-insurance. org/fileadmin/mcii/documents/MCII_2016_CRI_for_the_Poor_and_Vulnerable_full_study_lo-res.pdf

Skees RJ (2000) A role for capital markets in natural disasters: a piece of the food security puzzle. Food Policy 25:365-378

Skees J, Barnett B, Collier B (2008) Agricultural insurance background and context for climate adaptation discussions. GlobalAgRisk Inc, Lexington

Smit B (1994) Climate, compensation and adaptation. In: McCulloch J, Etkin D (eds) Proceedings of a workshop on improving responses to atmospheric extremes: the role of insurance and compensation. Environment Canada/The Climate Institute, Toronto

Smit B, Skinner MW (2002) Adaptation options in agriculture to climate change: a typology. Mitig Adapt Strateg Glob Chang 7:85-114

Surminski S, Bouwer ML, Linnerooth-Bayer J (2016) How insurance can support climate resilience. Nat Clim Chang 6:333-334

Varangis P, Skees JR, Barnett BJ (2002) Weather indexes for developing countries. In: Dischel RS (ed) Climate risk and the weather market: financial risk management and weather hedge. Risk Books, Risk Water Group, Ltd., London, pp 279-294

Vermeulen JS, Challinor JA, Thornton KP, Campbell MB, Eriyagamaa N, Vervoort MJ, Kinyangi J, Jarvis A, Läderach P, Ramirez-Villegas J, Nicklin JK, Hawkinsh E, Smith RD (2013) Addressing uncertainty in adaptation planning for agriculture. Proc Natl Acad Sci 110(21):8357-8362

Walker B, Holling CS, Carpenter SR, Kinzig A (2004) Resilience, adaptability and transformability in socialecological systems. Ecol Soc 9(2):5 http://www.ecologyandsociety.org/vol9/iss2/art5/ 
World Bank (2018) Brief: agriculture finance \& agriculture insurance. World Bank Group, Washington DC. http:/www.worldbank.org/en/topic/financialsector/brief/agriculture-finance. Accessed on 23 April 2019

World Food Programme (2017) WFP Ethiopia 2017 emergency situation report \#04. World Food Programme, Rome

Publisher's note Springer Nature remains neutral with regard to jurisdictional claims in published maps and institutional affiliations.

\section{Affiliations}

\section{Shahbaz Mushtaq ${ }^{1} \cdot$ Jarrod Kath $^{1} \cdot$ Roger Stone $^{1} \cdot$ Ross Henry $^{2} \cdot$ Peter Läderach $^{3}$ • Kathryn Reardon-Smith ${ }^{1}$ - David Cobon ${ }^{1} \cdot$ Torben Marcussen $^{1} \cdot$ Neil Cliffe $^{4} \cdot$ Paul Kristiansen $^{5}$. Frederik Pischke ${ }^{6}$}

Shahbaz Mushtaq

Shahbaz.Mushtaq@usq.edu.au

Jarrod Kath

Jarrod.Kath@usq.edu.au

Roger Stone

Roger.Stone@usq.edu.au

Ross Henry

Ross.Henry@qrida.qld.gov.au

Peter Läderach

p.laderach@cgiar.org

Kathryn Reardon-Smith

Kathryn.Reardon-Smith@usq.edu.au

David Cobon

David.Cobon@usq.edu.au

Torben Marcussen

Torben.Marcussen@usq.edu.au

Neil Cliffe

Neil.Cliffe@daf.qld.gov.au

Paul Kristiansen

pkristi2@une.edu.au

Frederik Pischke

frederik.pischke@gwp.org

1 Centre for Applied Climate Sciences, University of Southern Queensland, Toowoomba, Queensland 4350, Australia

2 Queensland Rural and Industry Development Authority, Turbot Street, Brisbane, Queensland, Australia

3 International Center for Tropical Agriculture, Hanoi, Vietnam

4 Rural Economic Development, Department of Agriculture and Fisheries, Mackay, Queensland, Australia

5 School of Environmental and Rural Science, University of New England, Armidale, NSW, Australia

6 Global Water Partnership (GWP) and World Meteorological Organization (WMO), Genève, Switzerland 